\title{
Clinical and epidemiological features of adenovirus keratoconjunctivitis in London
}

\author{
S. DAROUGAR, ${ }^{1}$ R. H. B. GREY, ' U. THAKER, ${ }^{1}$ AND D. A. McSWIGGAN ${ }^{2}$
}

From the 'Subdepartment of Virology, Institute of Ophthalmology, Judd Street, London WC1H 9QS, and the Virus Clinic, Moorfield's Eye Hospital, City Road, London ECIV 2PD; and the

${ }^{2}$ Public Health Laboratory, Central Middlesex Hospital, London NW10 7NS

SUMmaRY Ninety-eight patients were studied. Ninety were consecutive patients who were isolation-positive for adenovirus, and 8, who were associated with a hospital outbreak of adenovirus serotype 8 infection, developed characteristic features of infection but were isolation-negative. The ratio of males to females was 2 to 1 , and most patients were aged 20 to 39 . Adenovirus serotypes 3 , 7 , and 8 were isolated from $86 \%$ of patients, and serotypes $2,4,5,11,15$, and $15 / 29$ from the remaining $14 \%$. Adenovirus serotype 7 was more commonly isolated from patients under the age of 19 and was not isolated during winter. Sources of infection could be identified in $36 \%$ of patients and included contact with upper respiratory tract or ocular infections, a hospital outbreak, and a recent visit to a swimming pool. Associated systemic disease was detected in $47 \%$ of patients, most of whom had upper respiratory tract infection. The most severe and prolonged conjunctivitis was caused by serotypes 5 and 8. Most patients developed epithelial punctate keratitis. Subepithelial punctate keratitis, which was once considered to be a characteristic feature of adenovirus serotype 8 , developed in cases of serotype $3,4,5,7$, and 8 infection.

Adenovirus keratoconjunctivitis is a major cause of ocular morbidity in developed and developing countries. Epidemic keratoconjunctivitis (EKC) caused by adenovirus serotype 8 is well defined. It is characterised by outbreaks of keratoconjunctivitis and the development of corneal opacities and hazy vision, which can persist for several months or even years. The role of medical officers and ophthalmologists in the transmission of EKC is well recognised.

Ocular infections caused by other adenovirus serotypes have not been studied as thoroughly. Serotypes 3 and 7 are most commonly isolated from cases of sporadic keratoconjunctivitis, but many other serotypes have also been isolated. ${ }^{12}$ It has recently been recognised that adenovirus serotypes $10 / 19,19$, and 21 can produce clinical features similar to EKC. . $^{3-5}$

In this paper we report epidemiological and clinical details of 98 cases in London of adenovirus keratoconjunctivitis caused by various serotypes.

Correspondence to Professor S. Darougar, Institute of Ophthalmology, Judd Street, London WC1H 9 QS.

\section{Patients and methods}

Ninety-eight patients were included in this study. Ninety of these were consecutive patients attending the Virus Clinic, Moorfields Eye Hospital, London, from whom adenovirus was isolated. A further 8 patients were included who were isolation-negative but had characteristic features of serotype 8 infection, and who were known to be associated with a small hospital outbreak of serotype 8 infection.

The patient were examined by a Haag-Streit slitlamp. The clinical signs and symptoms were scored and recorded in accordance with the method described previously. ${ }^{6}$

\section{LABORATORY INVESTIGATIONS}

Differential cytology. Conjunctival scrapings were taken from 89 patients with an aluminium spatula in accordance with the method described earlier. ${ }^{7}$ Scrapings were placed on glass slides, fixed with methanol, stained with Giemsa, and examined microscopically at a magnification of $\times 400$ for the presence of inflammatory cells.

Virus isolation. A total of 210 specimens vere 
collected from 98 patients by scraping or swabbing the upper and lower lid conjunctiva. Specimens were placed in plastic capsules containing 2SP transport medium $^{8}$ and stored in a liquid nitrogen refrigerator until transported to the laboratory, where they were stored at a temperature of $-70^{\circ} \mathrm{C}$.

Each specimen was inoculated into 2 cultures of human embryonic kidney (HEK) cells, and examined for the presence of cytopathic effect (CPE) for up to 21 days.' Isolates were serotyped by means of a neutralisation test.

Serology. Two blood specimens were taken by venepuncture at an interval of 2 to 3 weeks from 42 patients. They were tested by a complement fixation test (CFT) for adenovirus group antibody. ${ }^{10}$

\section{Results}

SEROTYPES OF ISOLATES

Adenovirus serotypes 3,7 , and 8 were responsible for 84 out of $98(86 \%)$ of infections. Serotypes $2,4,5,11$, and 15 were also isolated (Table 1). Four isolates were identified as type 15 , and 3 of these cross-reacted with antiserum against serotype 29 . They are therefore presented as serotypes $15 / 29$.

\section{SEX AND AGE DISTRIBUTION}

The overall ratio of male to female was about 2 to 1 .

The age groups of patients at presentation are shown in Table 1. The majority of patients were aged between 20 and 39, but half of the patients with serotype 7 were under 20 years old.

\section{SEASONAL VARIATION}

Adenovirus serotype 7 was isolated during the spring and summer, whereas serotype 3 was isolated throughout the year (Table 2). The higher incidence of serotype 8 during August and September was due to a hospital outbreak. The incidence of other serotypes was too low for any conclusions regarding seasonal variation to be drawn.

SOURCES OF INFECTION

Eleven patients had contact with a relative, friend, or

Table 1 Adenovirus serotypes and ages of patients

\begin{tabular}{|c|c|c|c|c|c|c|c|c|c|}
\hline \multirow{2}{*}{$\begin{array}{l}\text { Age } \\
\text { (years) }\end{array}$} & \multicolumn{8}{|c|}{ Serotypes } & \multirow[t]{2}{*}{ Totals } \\
\hline & 2 & 3 & 4 & 5 & 7 & 8 & 11 & 15 and $15 / 29$ & \\
\hline 0-9 & - & 1 & - & - & 4 & 1 & - & - & 6 \\
\hline $10-19$ & - & 3 & 1 & - & 3 & 3 & - & 1 & 11 \\
\hline 20-29 & - & 11 & 1 & 2 & 3 & 9 & 1 & 2 & 29 \\
\hline 30-39 & 1 & 20 & 2 & - & 3 & 5 & - & 1 & 32 \\
\hline $40-49$ & - & 6 & - & 1 & - & 3 & - & - & 10 \\
\hline Over 50 & - & 2 & - & 1 & 1 & 6 & - & - & 10 \\
\hline Totals & 1 & 43 & 4 & 4 & 14 & $27^{*}$ & 1 & 4 & 98 \\
\hline
\end{tabular}

*Includes 8 isolation-negative patients known to be associated with a hospital outbreak of serotype 8.

Table 2 Seasonal distribution of adenovirus serotypes

\begin{tabular}{|c|c|c|c|c|c|c|c|c|c|}
\hline \multirow[t]{2}{*}{ Month } & \multicolumn{8}{|c|}{ Serotypes } & \multirow[t]{2}{*}{ Totals } \\
\hline & 2 & 3 & 4 & 5 & 7 & 8 & 11 & 15 and $15 / 29$ & \\
\hline January & 1 & 9 & 1 & - & - & - & - & - & 11 \\
\hline February & - & 2 & - & 1 & - & 1 & - & - & 4 \\
\hline March & - & 2 & - & 2 & 1 & 1 & - & - & 6 \\
\hline April & - & 4 & - & - & 2 & 2 & - & - & 8 \\
\hline May & - & 5 & 1 & - & 1 & - & 1 & 1 & 9 \\
\hline June & - & 3 & 1 & - & 2 & - & - & 1 & 7 \\
\hline July & - & 5 & - & - & 1 & 1 & - & - & 7 \\
\hline August & - & 3 & - & - & 3 & $6^{*}$ & - & 1 & 13 \\
\hline September & - & 2 & 1 & 1 & 3 & $13^{*}$ & - & - & 20 \\
\hline October & - & - & - & - & 1 & 2 & - & - & 3 \\
\hline November & - & 4 & - & - & - & - & - & 1 & 5 \\
\hline December & - & 4 & - & - & - & 1 & - & - & 5 \\
\hline Totals & 1 & 43 & 4 & 4 & 14 & 27 & 1 & 4 & 98 \\
\hline
\end{tabular}

*The higher incidence in August and September was due to a hospital outbreak. 
Table 3 Sources of ocular adenovirus infection

\begin{tabular}{|c|c|c|c|c|c|c|c|c|c|}
\hline \multirow[t]{2}{*}{ Source } & \multicolumn{8}{|c|}{ Serotypes } & \multirow[t]{2}{*}{ Totals } \\
\hline & 2 & 3 & 4 & 5 & 7 & 8 & 11 & 15 and $15 / 29$ & \\
\hline Hospital infection & - & 2 & - & - & 1 & 13 & - & - & 16 \\
\hline Ocular infection & - & 4 & 1 & - & - & 5 & - & 1 & 11 \\
\hline $\begin{array}{l}\text { Upper respiratory tract } \\
\text { infection }\end{array}$ & - & 4 & - & 1 & 1 & - & - & - & 6 \\
\hline Swimming Pool & - & - & - & - & 2 & - & - & - & 2 \\
\hline Unknown & 1 & 33 & 3 & 3 & 10 & 9 & 1 & 3 & 63 \\
\hline
\end{tabular}

Table 4 Systemic disease associated with ocular adenovirus infection

\begin{tabular}{|c|c|c|c|c|c|c|c|c|c|}
\hline \multirow[t]{2}{*}{ Systemic disease } & \multicolumn{8}{|c|}{ Serotypes } & \multirow[t]{2}{*}{ Totals } \\
\hline & 2 & 3 & 4 & 5 & 7 & 8 & 11 & 15 and $15 / 29$ & \\
\hline \multirow{4}{*}{$\begin{array}{l}\text { Upper respiratory tract } \\
\text { Fever/malaise } \\
\text { Gastro-intestinal tract } \\
\text { Total patients with one or } \\
\text { more systemic symptoms }\end{array}$} & - & $22(51)^{*}$ & $2(50)$ & $1(25)$ & $8(57)$ & $5(19)$ & - & $1(25)$ & $39(40)$ \\
\hline & - & $4(9)$ & - & - & 4 (29) & $5(19)$ & - & - & $13(13)$ \\
\hline & - & $1(2)$ & - & $1(25)$ & - & $2(7)$ & - & - & $4(4)$ \\
\hline & - & $24(63)$ & $2(50)$ & $1(25)$ & $8(57)$ & $10(37)$ & - & $1(25)$ & $46(47)$ \\
\hline
\end{tabular}

*Number of patients $(\%)$

colleague with conjunctivitis, 6 had contact with upper respiratory tract infection (URTI), 16 were associated with a hospital outbreak, and only 2 had recently been to a swimming pool (Table 3 ). Sixtythree patients $(64 \%)$ had no history of contact with conjunctivitis or URTI.

\section{HOSPITAL OUTBREAK}

During this study an outbreak of serotype 8 infection occurred at Moorfields Eye Hospital. Thirteen patients were infected in the casualty department while attending for other reasons, and 2 of these patients infected 3 relatives. The total number of patients associated with this outbreak was therefore 16.

The incubation period for the hospital infected patients was 2 to 11 days, and the majority developed conjunctivitis 7 to 9 days after their first visit. Seven of these patients were infected during minor surgical procedures: removal of foreign bodies (5), syringing of lacrimal canaliculi (1), and Schirmer test (1), 4 were infected during clinical examination, and 2 patients were staff in the casualty department (a medical officer and a nurse).

\section{ASSOCIATED SYSTEMIC DISEASE}

The prevalence of associated systemic disease in relation to different serotypes is shown in Table 4 . Patients with serotypes 3,4 , and 7 infections had a markedly higher prevalence of systemic disease compared with patients with other serotypes.

\section{LYMPHADENOPATHY}

Regional lymphadenopathy was detected in about $75 \%$ of patients. The majority of these patients had mild swelling of the preauricular nodes, accompanied by slight tenderness, but a few also had submandibular or cervical node involvement.

\section{CONJUNCTIVITIS}

Eighty-two patients attended regularly for follow-up and are included in this analysis. Ten patients (12\%) had bilateral conjunctivitis at onset. Forty-eight patients (59\%) developed bilateral conjunctivitis 3 to 7 days after onset. In 36 of these, the infection was worse in the first eye, and in the remaining 12 both eyes were equally badly affected (Table 5 ).

The mean duration of conjunctivitis for all serotypes was 20 days. It was shortest in serotype 11 infection (mean 11 days) and longest for serotype 5 infection (mean 37 days). Conjunctivitis was mild in serotypes 4 and 11 , moderate in serotypes $2,3,7,15$, and $15 / 29$, and severe in serotypes 5 and 8 (Table 6).

The prevalence and severity of clinical signs in the palpebral conjunctiva is shown in Table 6 and Fig. 1 . At first attendance all patients had moderate to severe hyperaemia, diffuse infiltration, and papillary hypertrophy. Most patients had follicular hypertrophy. The papillary reaction was more severe in the upper tarsal conjunctiva. The mean duration of 
Table 5 Clinical form of conjunctivitis in 82 patients with adenovirus infection

\begin{tabular}{|c|c|c|c|c|c|c|c|c|c|}
\hline \multirow[t]{2}{*}{ Clinical form } & \multicolumn{8}{|c|}{ Serotypes } & \multirow[t]{2}{*}{ Totals } \\
\hline & 2 & 3 & 4 & 5 & 7 & 8 & 11 & 15 and $15 / 29$ & \\
\hline Patients & 1 & 36 & 4 & 3 & 12 & 21 & 1 & 4 & 82 \\
\hline Unilateral $^{*}$ & 1 & $10(28)$ & - & $2(67)$ & $4(34)$ & $6(29)$ & 1 & - & $24(29)$ \\
\hline Bilateral onset* & - & $6(17)$ & - & $1(33)$ & $2(16)$ & $1(5)$ & - & 一 & $10(12)$ \\
\hline Unilateral becoming & & & & & & & & & \\
\hline bilateral $^{*}$ & - & $20(55)$ & $4(100)$ & - & $6(50)$ & $14(66)$ & 一 & $4(100)$ & $48(59)$ \\
\hline $\begin{array}{l}\text { Mean days to onset in } \\
\text { second eye }\end{array}$ & - & 7 & 5 & - & 3 & 7 & - & 6 & 6 \\
\hline First eye worse & - & 16 & 2 & - & 3 & 12 & - & 3 & 36 \\
\hline Second eye worse & - & - & - & - & - & - & - & - & - \\
\hline Eyes equally affected & - & 4 & 2 & - & 3 & 2 & - & 1 & 12 \\
\hline
\end{tabular}

*Number of patients (\%).

Table 6 Conjunctival inflammatory responses in 82 patients with adenovirus infection

\begin{tabular}{|c|c|c|c|c|c|c|c|c|c|}
\hline \multirow[t]{2}{*}{ Conjunctival responses } & \multicolumn{8}{|l|}{ Serotypes } & \multirow[t]{2}{*}{ Totals } \\
\hline & 2 & 3 & 4 & 5 & 7 & 8 & 11 & 15 and $15 / 29$ & \\
\hline $\begin{array}{l}\text { Mean duration of acute } \\
\text { conjunctivitis } \\
\text { Mean severity of }\end{array}$ & 15 & 19 & 19 & 37 & 17 & 28 & 11 & 22 & \\
\hline conjunctivitis* & 19 & 20 & 14 & 21 & 16 & 24 & 12 & 20 & \\
\hline Papillary hypertrophy ${ }^{\dagger}$ & $1(100)$ & $36(100)$ & $4(100)$ & $3(100)$ & $12(100)$ & $21(100)$ & $1(100)$ & $4(100)$ & $82(100)$ \\
\hline $\begin{array}{l}\text { Follicular hypertrophy }{ }^{\dagger} \\
\text { Punctate coniunctival }\end{array}$ & $1(100)$ & $35(97)$ & $4(100)$ & $3(100)$ & $11(92)$ & $20(95)$ & $1(100)$ & $4(100)$ & $79(96 \%)$ \\
\hline haemorrhage ${ }^{\dagger}$ & - & $8(22)$ & - & - & $3(25)$ & $3(14)$ & - & $1(25)$ & $15(18)$ \\
\hline Pseudomembrane ${ }^{\dagger}$ & - & - & - & - & $2(17)$ & $8(38)$ & - & - & $10(12)$ \\
\hline Conjunctival scarring ${ }^{\dagger}$ & - & $2(6)$ & - & - & $1(8)$ & $6(29)$ & - & - & $9(11)$ \\
\hline
\end{tabular}

${ }^{*}$ Degree of severity (mild 5-14, moderate $15-20$, severe $>20$ ).

+Number of patients with response $(\%)$.

moderate to severe papillary responses was 2 to 3 weeks for serotypes $4,7,15$, and $15 / 29,4$ weeks for serotype 5 , and 7 weeks or more for serotypes 3 and 8 (Fig. 1). A mild papillary reaction persisted in most cases for several weeks.

Moderate follicular responses were observed, mainly in the lower and upper fornices, in $79(96 \%)$ patients. Follicles were rather small and discrete. The mean duration and severity of this response was similar to that of papillary responses (Fig. 1).

Punctate conjunctival haemorrhages were found in $15(18 \%)$ patients. These patients had serotypes 3,7 , 8,15 , and 15/29 infections (Table 6). The incidence of haemorrhages was similar for all these serotypes and was not always associated with severe conjunctivitis.

Pseudomembrane was observed in $10(12 \%)$ patients. Eight of these were infected with serotype 8, and 2 were infected with serotype 7; all had severe keratoconjunctivitis (Table 6).

Moderate to severe linear or diffuse scarring developed in 9 patients $(11 \%)$. They were infected with serotypes 3,7 , or 8 (Table 6 ). Seven of these patients had severe conjunctivitis, and 2 had moderate disease. There was no distortion of lids resulting from conjunctival scarring, nor was there any impairment of tear production.

\section{KERATITIS}

Of the 82 patients who were followed up regularly 59 (72\%) developed epithelial punctate keratitis (EPK) and $35(43 \%)$ developed subepithelial punctate keratitis (SEPK) (Table 7, Fig. 2).

Approximately half of patients with serotypes 3, 15 , and 15/29 infections and most patients with serotype 4, 5, 7, 8, and 11 infections developed EPK. The mean duration of EPK was under 2 weeks, except for serotype 8 infection, in which the mean duration was just over 3 weeks. Corneal infiltrates were small, punctate, and slightly elevated. There were no distinctive features between EPK caused by different serotypes except for serotype 8 infections, in which lesions tended to be coarse, and progressed toward subepithelial lesions. The severity of EPK was mild to moderate in all cases except for the 2 patients with 

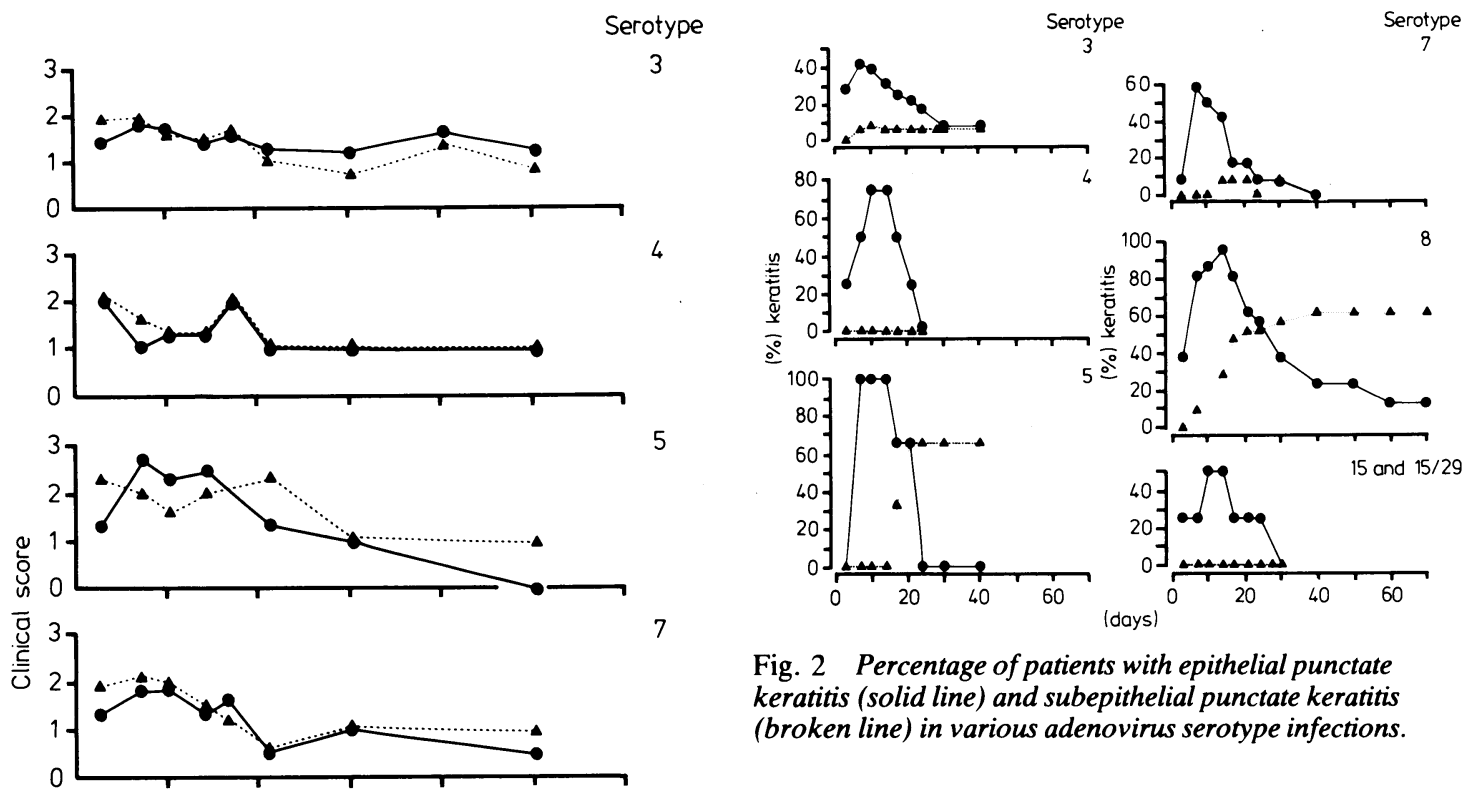

Fig. 2 Percentage of patients with epithelial punctate keratitis (solid line) and subepithelial punctate keratitis (broken line) in various adenovirus serotype infections.

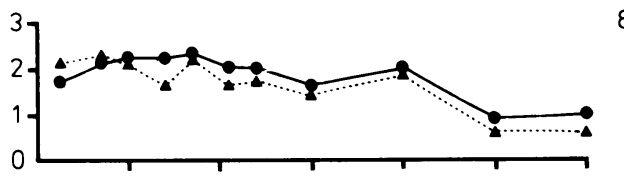

except one patient, who had mild SEPK for more than 8 months. Adenovirus serotype 8 produced the most severe and most prolonged SEPK. In the sporadic cases SEPK resolved in less than 6 weeks in 2 cases, but it persisted for at least one year in one case and for more than 2 years in another. Three more cases had SEPK after 4 months but did not reattend. In the epidemic cases SEPK in 3 patients resolved in 2 to 3 weeks, 6 had SEPK 4 months later, 2 had opacities for over 2 years, and in one patient SEPK was observed over 4 years.

Stromal diffuse infiltration and/or oedema

Fig. 1 Mean severity of papillary responses (solid line) and follicular responses (broken line) in various adenovirus serotype infections. Clinical score $1=$ mild, $2=$ moderate, $3=$ severe.

serotype 8 infection, who had severe epithelial involvement with considerable erosion.

In our patients SEPK was generally coarse and visible to the naked eye. In severe cases lesions tended to merge. SEPK was observed in patients with serotype $3,4,5,7$, and 8 infections. The highest incidence of SEPK was associated with serotypes 5 and 8 (Table 7). In some cases the duration of SEPK could not be assessed accurately because patients failed to attend for follow-up when they had been free of symptoms for several weeks. In the 2 patients with serotype 7 infection SEPK resolved within 3 weeks, and in the patients with serotype 4 or 5 infection it lasted for one to 4 months. In serotype 3 infection SEPK resolved completely within 5 weeks in all occurred in 4 patients, 2 with serotype 8 , one with serotype 3 , and one with serotype 7 infection. The appearance was similar to that of mild disciform keratitis, more usually associated with herpes simplex virus infection. The corneal infiltration and/or oedema resolved rapidly, but in the 2 serotype 8 cases SEPK developed subsequently.

\section{UVEITIS}

A mild anterior uveitis occurred in 3 patients with serotype 8 infection. All 3 had severe punctate keratitis, and 2 also had diffuse stromal keratitis. The uveitis was characterised by a mild flare and small numbers of cells in the aqueous of the anterior chamber. The uveitis resolved within a few days without complications.

DIFFERENTIAL CYTOLOGY

Conjunctival scrapings taken from 89 patients in early stages of infection showed inflammatory infiltrates in which lymphocytes predominated. 
Table 7 Prevalence of corneal signs in 82 cases of adenovirus infection

\begin{tabular}{llllllllll}
\hline Corneal signs & \multicolumn{1}{l}{ Serotype } & \multicolumn{1}{l}{} & & & Totals \\
\cline { 2 - 10 } & 2 & 3 & 4 & 5 & 7 & 8 & 11 & 15 and $15 / 29$ \\
\hline $\begin{array}{l}\text { Epithelial punctate } \\
\text { keratitis }\end{array}$ & - & $20(56 \%)^{*}$ & $3(75)$ & $3(100)$ & $10(83)$ & $20(95)$ & $1(100)$ & $2(50)$ & $59(72)$ \\
$\begin{array}{l}\text { Subepithelial punctate } \\
\text { keratitis }\end{array}$ & - & $9(25)$ & $1(25)$ & $3(100)$ & $2(17)$ & $20(95)$ & - & - & $35(44)$ \\
$\begin{array}{l}\text { Stromal diffuse infiltration } \\
\text { and/or oedema }\end{array}$ & - & $1(3)$ & - & - & $1(8 \%)$ & $2(10)$ & - & - & $4(5)$ \\
\hline
\end{tabular}

*Number of patients $(\%)$.

Table 8 Results of complement fixation test in 42 paired sera

\begin{tabular}{llllllllll}
\hline & \multicolumn{1}{l}{ Serotypes } & \multicolumn{1}{c}{ Totals } \\
\cline { 2 - 9 } & 2 & 3 & 4 & 5 & 7 & 8 & 11 & 15 and 15/29 \\
\hline Positive* & $1(100 \%)$ & $9(57 \%)$ & 0 & $3(75 \%)$ & $2(67 \%)$ & $11(79 \%)$ & 0 & $1(33 \%)$ & $27(64 \%)$ \\
Total tested & 1 & 16 & 1 & 4 & 3 & 14 & 0 & 3 & 42 \\
\hline
\end{tabular}

*Four-fold or greater rise in titre.

\section{SEROLOGY}

A complement fixation test was performed on paired sera from 42 patients. An increase in antibody level (4-fold or greater) was observed in $27(64 \%)$ of the patients tested (Table 8).

\section{Discussion}

In this study the majority of patients with ocular adenovirus infection were adults aged between 20 and 39 years. Nearly half had associated disease, the most common being upper respiratory tract infection $(40 \%)$ and the rarest gastrointestinal tract infection (4\%).

Adenovirus serotype 3 was most commonly isolated from our patients. Serotypes 7 and 8 were less common, and other serotypes $(2,4,5,11,15$, and 15/29) were rare.

Adenovirus serotype 2, which is a common cause of respiratory infection, ${ }^{2}$ was isolated from only one patient. Conjunctivitis was mild and unilateral, with no keratitis or systemic symptoms.

Adenovirus serotype 3 infection was most common. The majority of patients were adult, and only $9 \%$ were less than 20 years old. Serotype 3 infection had the highest incidence of associated systemic disease $(63 \%)$. Corneal lesions occurred in $56 \%$ of patients, and SEPK developed in a quarter of our cases, lasting from one to 4 months. Some of these findings are similar to those of Ormsby et al. ${ }^{11}$ who reported that most of their patients with serotype 3 infection were adults and that 10 out of $24(42 \%)$ developed corneal opacities.
In the 4 cases of serotype 4 infection conjunctivitis was mild and lasted for an average of 2 weeks. A mild EPK occurred in 3 cases, and one of these developed SEPK. Two patients also had upper respiratory tract infection. These observations can be compared with those made during an outbreak of serotype 4 infection, ${ }^{12}$ in which the average duration of symptoms was 14 days. Of the patients studied $12 \%$ had concurrent respiratory symptoms, $24 \%$ had corneal signs, $13 \%$ had EPK, and $16 \%$ had SEPK.

Adenovirus serotype 5 was associated with prolonged, severe conjunctivitis, and keratitis. Patients with serotype 5 infection could not be distinguished clinically from patients with EKC (caused by serotype 8), although they generally had fewer SEPK infiltrates.

A generally mild disease was associated with adenovirus serotype 7 infection. Conjunctivitis was moderate, and the mean duration was 17 days, a little shorter than the average duration (20 days). While $83 \%$ of patients developed EPK, only $17 \%$ of these developed SEPK, which resolved within 4 weeks. Patients were generally younger (half were under 20 years), and no cases occurred in winter. These observations are similar to those of Ormsby et al., ${ }^{11}$ who found that most patients were children and that cases occurred only in the summer.

Adenovirus serotype 8 caused the most severe conjunctivitis, and most patients developed EPK and SEPK. However, serotype 8 infections could not be diagnosed on clinical grounds alone because they were similar to serotype 5 infections. The highest incidences of pseudomembrane (38\%) and con- 
junctival scarring (28\%) were found in these patients, but were lower than those reported in another outbreak of EKC, in which over half of patients had pseudomembranes and conjunctival scarring. ${ }^{13}$ The incidence of systemic symptoms in our patients was lower than that for serotypes 3,4 , and 7 .

Serotypes 11,15 , and $15 / 29$.were associated with mild to moderate conjunctivitis, lasting for about 2 or 3 weeks. EPK was mild and transient, lasting for a few days.

The conjunctivitis caused by the different serotypes was very similar, though it varied in severity and duration. Although SEPK was originally considered to be characteristic of serotype 8 infection, it has been reported that other serotypes can also cause SEPK. ${ }^{13}$ In this study we observed SEPK in infections caused by serotypes $3,4,5,7$, and 8 . However, the incidence, severity, and duration of SEPK varied considerably between different serotypes.

We are grateful to colleagues at Moorfields Eye Hospital for referring patients to the Virus Clinic, and to Dr M. A. Monnickendam for a critical reading of this paper.

This study was supported by a grant from the Locally Organised Research Scheme, Moorfields Eye Hospital.

\section{References}

1 Editorial. Adenovirus keratoconjunctivitis. $\mathrm{Br} \mathrm{J}$ Ophthalmol 1977; 61: 73-5.
2 Darougar S, Walpita P, Thaker U, Viswalingam N, Gardner L, McSwiggan DA. Adenovirus serotypes isolated from ocular infections in London. Br J Ophthalmol (paper 104/82).

3 Bell EJ. Winton FW. Keratoconjunctivitis caused by adenovirus type 19. Br Med J 1975; i: 91.

4 Tullo AB, Higgins PG. An outbreak of adenovirus keratoconjunctivitis in Bristol. Br J Ophthalmol 1979; 63: 621-6.

5 Darougar S, Pearce R, Gibson JA, McSwiggan DA. Adenovirus type 21 keratoconjunctivitis. Br J Ophthalmol 1978; 62: 836-7.

6 Darougar S, Viswalingam N, Treharne JD, Kinnison JR, Jones BR. Treatment of TRIC infection of the eye with rifampicin or chloramphenicol. Br J Ophthalmol 1977; 61: 255-9.

7 Darougar S, Jones BR. Conjunctival swabbing for the isolation of TRIC agent (Chlamydia). Br J Ophthalmol 1971; 55: 585-90.

8 Gordon FB, Harper IA, Quan Al, Treharne JD, Dwyer RST, Garland JA. Detection of chlamydia (Bedsonia) in certain infections of man. 1. Laboratory procedures: comparison of yolk sac and cell culture for detection and isolation. J Infect Dis 1969; 120: 451-62.

9 McSwiggan DA, Darougar S, Rahman AFMS, Gibson JA. Comparison of the sensitivity of human embryo kidney cells, HeLa cells and W138 cells for the primary isolation of viruses from the eye. J Clin Pathol 1975; 28: 410-3.

10 Bradstreet CM, Taylor CED. Technique of complement-fixation test applicable to the diagnosis of virus disease. Monthly Bulletin of the Ministry of Health and Public Health Laboratory Service 1962; 21: 96-104.

11 Ormsby HL, Fowle AMC, Doane F. Canadian cases of adenovirus infection 1951-1956. Am J Ophthalmol 1957; suppl: 17-20.

12 Tullo AB, Higgins PG. An outbreak of adenovirus type 4 conjunctivitis. Br J Ophthalmol 1980; 64: 489-93.

13 Dawson CR, Hanna L, Togni B. Adenovirus type 8 infections in the United States. IV. Observations on the pathogenesis of lesions in severe eye disease. Arch Ophthalmol 1972; 87: 258-68. 